\title{
Vitrectomy for Proliferative Diabetic Retinopathy Associated with Klinefelter Syndrome
}

\author{
Kensuke Tajiri Kohei Otsuki Takaki Sato Daisaku Kimura \\ Takatoshi Kobayashi Teruyo Kida Jun Sugasawa Tsunehiko Ikeda \\ Department of Ophthalmology, Osaka Medical College, Takatsuki, Osaka, Japan
}

\section{Key Words}

Klinefelter syndrome $\cdot$ Diabetic retinopathy $\cdot$ Vitrectomy $\cdot$ Blood coagulopathy

\begin{abstract}
Introduction: We encountered a patient with Klinefelter syndrome (KS) who experienced poor outcomes after vitrectomy for proliferative diabetic retinopathy (PDR). Case: A 44-yearold male with poorly controlled diabetes was diagnosed with KS by chromosome analysis. Ocular findings revealed severe PDR complicated with extensive preretinal hemorrhages and traction retinal detachment in his left eye, and pars plana vitrectomy was subsequently performed for treatment. Results: A clotting hemorrhage developed during surgery and proved difficult to control. Due to postoperative bleeding and redetachment, the vitrectomy was repeated. At the second operation, we performed a silicone oil tamponade; however, the retina was redetached under the silicone oil, and the light perception vision ultimately disappeared. Conclusion: The patient, despite showing increased blood coagulability due to diabetes, presented severe coagulopathy, likely related to KS. In patients with KS and severe PDR, the potential difficulty of vitrectomy should always be kept in mind.
\end{abstract}

(C) 2015 The Author(s)

Published by S. Karger AG, Basel

\section{Introduction}

Klinefelter syndrome (KS) is a sex chromosome abnormality in which a male is born with an extra $\mathrm{X}$ chromosome and it is the most common cause of hypogonadism $[1,2]$. The incidence of KS is about 1 in every 1,000 male newborns, with no differences reported among ethnic groups. KS is often discovered in adult males due to infertility, and is many

KARGER 125:s $\quad \begin{aligned} & \text { Tsunehiko Ikeda, MD } \\ & \text { Department of Ophthalmology, Osaka Medical College } \\ & \text { 2-7 Daigaku-machi } \\ & \text { Takatsuki, Osaka 569-8686 (Japan) } \\ & \text { E-Mail tikeda@poh.osaka-med.ac.jp }\end{aligned}$


Tajiri et al.: Vitrectomy for Proliferative Diabetic Retinopathy Associated with Klinefelter Syndrome

times associated with diabetes [3]. However, severe proliferative diabetic retinopathy (PDR) in KS has seldom been reported [4]. In this study, we report the case of a patient with KS and PDR who underwent vitrectomy. This patient experienced clotting hemorrhages during surgery that were difficult to control and extremely refractory to treatment.

\section{Case History}

Around September 2008, a 44-year-old male patient began noticing decreased visual acuity (VA) in both eyes but failed to seek treatment. On April 21, 2009, he noticed a sudden deterioration in VA in his left eye. PDR was diagnosed by a local ophthalmologist, and the patient was referred to our hospital 6 days later. He was also diagnosed with type 2 diabetes at 23 years of age, at which time insulin therapy was started. However, regular follow-up visits were not maintained, and his diabetes was not well controlled. The patient had also been diagnosed with diabetic nephropathy and neuropathy at the age of 32, but failed to undergo any eye examinations. Chromosome analysis (G-band method) performed that same year due to infertility revealed a 47,XXY karyotype, and he was ultimately diagnosed with KS (fig. 1). The patient also underwent surgery for a pituitary tumor (Rathke's cleft cyst) at that time, and concomitant hyperlipidemia and hypertension were noted. He was obese, with a height of $184 \mathrm{~cm}$ and a weight of $126.7 \mathrm{~kg}$.

The results of a blood test performed on April 21, 2009, were as follows: white blood cells: 7,700 / $\mu$; red blood cells: $424 \times 104 / \mu \mathrm{l}$; hemoglobin $(\mathrm{Hb}): 12.2 \mathrm{~g} / \mathrm{dl}$; platelets: $21.9 \times$ 104/ $\mu$; bleeding duration: $1 \mathrm{~min}$; C-peptide $(2 \mathrm{~h}): 3.5 \mathrm{mg} / \mathrm{ml}$; anti-glutamic acid decarboxylase antibody: negative; glutamic oxaloacetic transaminase: $19 \mathrm{IU} / \mathrm{l}$; guanosine triphosphate: $15 \mathrm{IU} / \mathrm{l} ; \gamma$-glutamyltranspeptidase: $34 \mathrm{IU} / \mathrm{l}$; alkali phosphatase: $276 \mathrm{IU} / \mathrm{l}$; amylase: 59 IU/l; lipid: $52 \mathrm{IU} / \mathrm{l}$; uric acid: $639 \mathrm{mg} / \mathrm{dl}$; creatinine: $1.25 \mathrm{mg} / \mathrm{dl}$; total cholesterol: $286 \mathrm{mg} / \mathrm{dl}$; triglyceride: $256 \mathrm{mg} / \mathrm{dl}$, and HbA1c: $8.6 \%$. Urine protein was (++). HbA1c varied greatly during the course from 6.5 to $13.8 \%$.

\section{Ocular Findings on Initial Evaluation}

The patient's ocular findings on initial examination were as follows: VA: right ventricular $=0.07$ (0.8 $\times$ S-5.0 D); left ventricular $=0.02$ (noncorrigunt); intraocular pressure: right eye $=16 \mathrm{~mm} \mathrm{Hg}$; left eye $=16 \mathrm{~mm} \mathrm{Hg}$. Exotropia of the left eye was identified. Examination of the anterior eye segment showed no abnormalities, but examination of the optic media showed mild bilateral cataracts (Emery grade $1+$ posterior subcapsular opacification). Funduscopy showed PDR in both eyes, and extensive fundal hemorrhages and deposit of hard exudates in the central fovea of the right eye were found (fig. 2a). Extensive preretinal hemorrhages, mainly in the posterior pole, were also seen in the left eye (fig. $2 \mathrm{~b}$ ). Fluorescein funduscopy of the right eye showed extensive nonperfused areas of the retina, but without neovascularization (fig. 2c). The left eye displayed blockage due to extensive preretinal hemorrhages, areas of nonperfused retina, and dye leakage due to neovascularization (fig. 2d). 
Tajiri et al.: Vitrectomy for Proliferative Diabetic Retinopathy Associated with Klinefelter Syndrome

\section{Clinical Course after Initial Evaluation}

Retinal photocoagulation (total: 647 shots) was performed where possible for the left eye. B-mode ultrasonography showed traction retinal detachment during the course, so phacoemulsification and aspiration, intraocular lens insertion, and vitrectomy were performed on May 22, 2009. We did not perform intravitreal injection of anti-vascular endothelial growth factor antibody agent before surgery. Intraoperative findings during vitrectomy showed that the posterior vitreous was still attached, and firm vitreoretinal adhesions were present. After the core vitrectomy, the posterior vitreous membrane was removed with vitreous forceps, and blood was aspirated from beneath the posterior vitreous membrane. The fibrovascular membrane around the vascular arcade was removed from the optic disc with a vitreous cutter and vitreous scissors. Extensive clotting hemorrhage was seen during surgery (fig. 3a).

During surgery, the systolic blood pressure was very high (190-220 mm Hg), and intravenous infusion of nicardipine hydrochloride was frequently required $(0.25 \mathrm{mg} \times 4,0.5 \mathrm{mg} \times$ 2; total: $2.0 \mathrm{mg}$ ). However, the blood pressure remained difficult to control. The membrane was excised while aspirating blood as necessary, but multiple iatrogenic tears were identified (fig. 3b). Finally, pneumatic retinopexy, intraocular photocoagulation, and gas tamponade with $20 \%$ SF6 were performed to complete the surgery.

However, marked precipitation of fibrin was seen in the anterior chamber the day after surgery. Besides a decrease in gas, bleeding occurred in the vitreous, as well as retinal redetachment. Thus, vitrectomy was performed again under general anesthesia on June 9, 2009. After removal of the residual vitreous, as much fibrin membrane as possible was removed from the retinal surface using vitreous forceps (fig. 3c). The retina had become extensively organized and contracted, so inferior retinectomy had to be performed to flatten the retina. Next, the retina was flattened with liquid perfluorocarbon, and intraocular photocoagulation was performed (fig. 3d). Finally, the liquid perfluorocarbon was replaced with silicone oil to complete the surgery. The intraoperative blood pressure control was satisfactory. Postoperatively, severe inflammation of the anterior chamber was identified, and fundus visibility remained poor. On November 5, 2009, the patient's retina had again detached, even with the silicone oil, and his intraocular pressure was approximately $10 \mathrm{~mm} \mathrm{Hg}$. Since no light perception was present in his left eye, no further surgery was performed. During follow-up, panretinal photocoagulation was performed on his right eye, and the corrected VA was maintained at 0.7 .

\section{Discussion}

First reported by Klinefelter in 1942 [1], KS is a sex chromosome abnormality due to an extra X sex chromosome. The karyotype is $47, \mathrm{XXY}$ in approximately $90 \%$ of the cases, but in the remaining approximately $10 \%$, a $46, \mathrm{XY} / 47, \mathrm{XXY}$ mosaic, or more rarely, $48, \mathrm{XXXY}$, $48, \mathrm{XXYY}, 49, \mathrm{XXXXY}$, and 49,XXXYY karyotypes have been reported [2]. The incidence of KS is about 1 in every 1,000 male newborns, with no reported differences apparent among ethnic groups. KS is often identified in adult males due to infertility, and in fact, $2.8 \%$ of the males with infertility have KS.

In regard to the clinical features, primary sex characteristics in KS are usually similar to those of normal males, but based on secondary sex characteristics, males with KS often have a shorter torso, longer neck, arms, and legs, and a delicate, slender build. 
Tajiri et al.: Vitrectomy for Proliferative Diabetic Retinopathy Associated with Klinefelter Syndrome

However, some males with KS are obese and show average height. Because of the extra $\mathrm{X}$ sex chromosome, features such as gynecomastia are common. Males with KS show very low sperm counts and tend to become infertile. Treatment usually involves male hormone replacement therapy.

Patients with KS display a higher incidence of male breast cancer and extragonadal germ cell tumors (primarily mediastinal germ cell tumors). The incidence of osteoporosis and autoimmune disorders is also high. About $15-50 \%$ of the males with KS in Western countries have diabetes, most often mild type 2 diabetes [3].

Ocular disorders in KS include uveal coloboma [5], choroidal atrophy [6], retinal degeneration [7], retinal vascular hypoplasia [8], cataracts [9], glaucoma [9], microphthalmia [10], and aniridia [11]. However, diabetic retinopathy has seldom been reported [4], and to the best of our knowledge, there have been no previous reports of severe PDR requiring vitrectomy. The reason why diabetic retinopathy has seldom been reported despite the relatively high incidence of diabetes in KS remains unclear. As mentioned previously, one reason might be that diabetes in KS is usually mild. However, our patient had very poorly controlled diabetes and had not undergone regular eye examinations, which may have contributed to the severe retinopathy.

Besides hypercoagulability due to diabetes, coagulopathy related to KS may have been a factor associated with the increased clotting tendency in our patient during vitrectomy. Thrombogenesis due to an increased estrogen/testosterone ratio and clotting gene abnormalities have been reported in KS [12].

The incidence of deep vein thrombosis in KS is 22.8 per 10,000 patient-years, and the incidence of pulmonary embolism is 16 per 10,000 patient-years. Reportedly, this incidence of venous thrombosis in KS is about 5-20 times higher than in normal healthy males [12]. Moreover, thrombogenesis is increased in KS due to an increased estrogen/testosterone ratio. Estrogen increases platelet aggregation and viscosity, increases levels of clotting factors VII, IX, and X, prothrombin and fibrinogen, and affects fibrinolytic activity associated with testosterone. Gene abnormalities of clotting and fibrinolytic factors involving G1691A factor V and a G2021A prothrombin mutation have also been reported [13]. Unfortunately, these factors were not examined in our patient, so we cannot exclude the possibility that such factor abnormalities may have contributed to the disease pathogenesis.

Poorly controlled blood pressure during the first vitrectomy may also have been a factor contributing to the severe intraoperative bleeding. During this first surgery, a total of $2.0 \mathrm{mg}$ of nicardipine hydrochloride, a calcium antagonist, was administered by intravenous infusion. However, given that the patient weighed $116.45 \mathrm{~kg}$ at the time of surgery, this dose per body weight was probably not excessive. Repeat surgery was performed under general anesthesia, and intraoperative blood pressure was well controlled without using antihypertensive drugs.

Much remains unclear about the association between KS and hypertension, but some hormonal abnormalities are probably involved. Gotoh et al. [14] reported severe low renin hypertension in a KS patient with Rathke's cleft cyst. Our patient had also undergone surgery for Rathke's cleft cyst, which may also have been a related factor. Although our patient had no pulmonary abnormalities, Agarwal and Dekam [15] reported pulmonary hypertension in a patient with KS.

In conclusion, our patient with KS and severe PDR may have had an underlying blood coagulopathy. The potential difficulty of vitrectomy in such cases compared to other patients should always be kept in mind. 
Tajiri et al.: Vitrectomy for Proliferative Diabetic Retinopathy Associated with Klinefelter Syndrome

\section{Acknowledgement}

The authors wish to thank John Bush for editing the manuscript.

\section{Statement of Ethics}

This case study has been approved by the Ethics Committee of the Osaka Medical College.

\section{Disclosure Statement}

There are no conflicts of interest to report for all authors.

\section{References}

1 Klinefelter HF, Reifenstein EC, Albright F: Syndrome characterized by gynaecomastia, aspermatogenesis without a-leydigism, and increased excretion of follicle stimulating hormone. J Clin Endocrinol Metab 1942;2:615-627.

-2 Bradbury JT, Bunge RG, Boccabella RA: Chromatin test in Klinefelter's syndrome. J Clin Endocrinol Metab 1956;16:689.

3 Bojesen A, Høst C, Gravholt CH: Klinefelter's syndrome, type 2 diabetes and the metabolic syndrome: the impact of body composition. Mol Hum Reprod 2010;16:396-401.

-4 Schmidt F, Kapellen TM, Wiegand S, Herbst A, Wolf J, Fröhlich-Reiterer EE, Rabl W, Rohrer TR, Holl RW; DPV-Wiss Study Group; BMBF Competence Network Diabetes: Diabetes mellitus in children and adolescents with genetic syndromes. Exp Clin Endocrinol Diabetes 2012;120:579-585.

5 Hashmi MS, Karseras AG: Uveal colobomata and Klinefelter syndrome. Br J Ophthalmol 1976;60:661-664.

-6 Verstraeten S, Jaenen N, Spileers W, de Ravel T, Casteels I: Diffuse choroidal atrophy in a boy with Klinefelter syndrome. J Pediatr Ophthalmol Strabismus 2011;48:64.

7 Karampelas M, Gardner J, Holder G, Hardcastle A, Webster A: Retinal dysfunction and high myopia in association with 48,XXYY syndrome. Doc Ophthalmol 2013;127:245-247.

-8 Fowell SM, Greenwald MJ, Prendiville JS, Jampol LM: Ocular findings of incontinentia pigmenti in a male infant with Klinefelter syndrome. J Pediatr Ophthalmol Strabismus 1992;29:180-184.

-9 Pamuk BO, Torun AN, Kulaksizoglu M, Algan C, ertugrul DT, Yilmaz Z, Tutuncu NB, Demirag NG: 49,XXXXY syndrome with autoimmune diabetes and ocular manifestations. Med Princ Pract 2009;18:482-485.

-10 Juhn AT, Nabi NU, Levin AV: Ocular anomalies in an infant with Klinefelter syndrome. Ophthalmic Genet 2012;33:232-234.

11 Pashayan H, Dallaire L, MacLeod P: Bilateral aniridia, multiple webs and severe mental retardation in a 47,XXY-48,XXXY mosaic. Clin Genet 1973;4:125-129.

12 Campbell WA, Price WH: Venous thromboembolic disease in Klinefelter's syndrome. Clin Genet 1981;19:275-280.

13 Lapecorella M, Marino R, De Pergola G, Scaraggi FA, Speciale V, De Mitrio V: Severe venous thromboembolism in a young man with Klinefelter's syndrome and heterozygosis for both G20210A prothrombin and factor V Leiden mutations. Blood Coagul Fibrinolysis 2003;14:95-98.

14 Gotoh M, Nakano J, Midorikawa S, Niimura S, Ono Y, Mizuno K: Multiple endocrine disorders and Rathke's cleft cyst with Klinefelter's syndrome: a case report. Endocr J 2002;49:523-529.

15 Agarwal S, Dekam MJ: Multiple cardiac anomalies in an elderly man with Klinefelter's syndrome. Singapore Med J 2011;52:e15-e17. 


\section{Case Reports in \\ Ophthalmology}
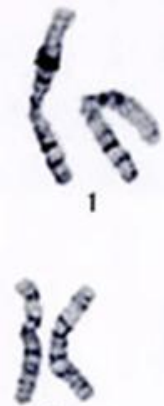

6

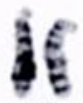

13
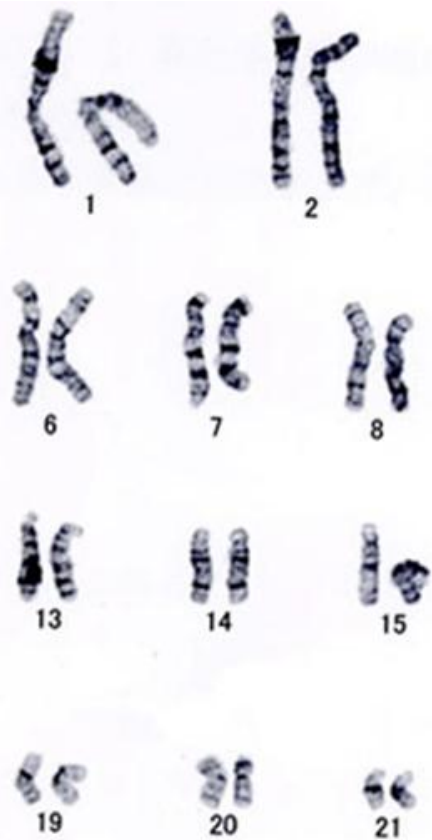

\begin{tabular}{l|l}
\hline Case Rep Ophthalmol 2015;6:420-426 \\
\hline DOI: $10.1159 / 000442461$ & $\begin{array}{l}\text { (c) } 2015 \text { The Author(s). Published by S. Karger AG, Basel } \\
\text { www.karger.com/cop }\end{array}$
\end{tabular}

Tajiri et al.: Vitrectomy for Proliferative Diabetic Retinopathy Associated with Klinefelter Syndrome
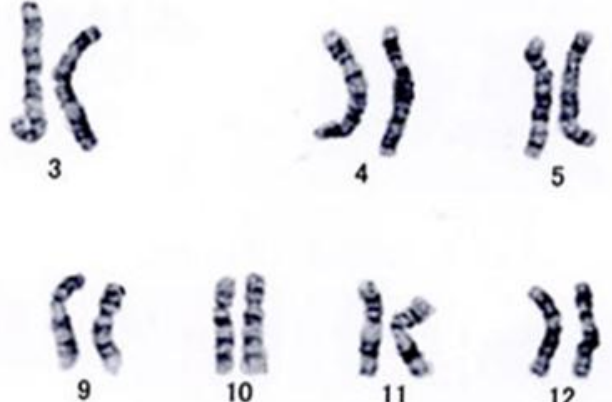

11

12
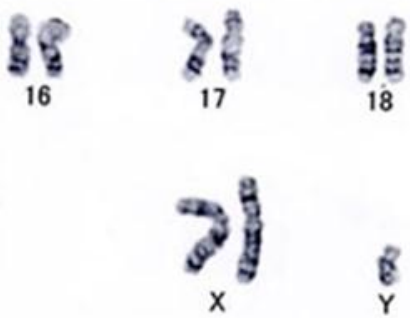

Fig. 1. Results of the chromosome analysis (G-band method). The karyotype was 47,XXY, and KS was diagnosed.
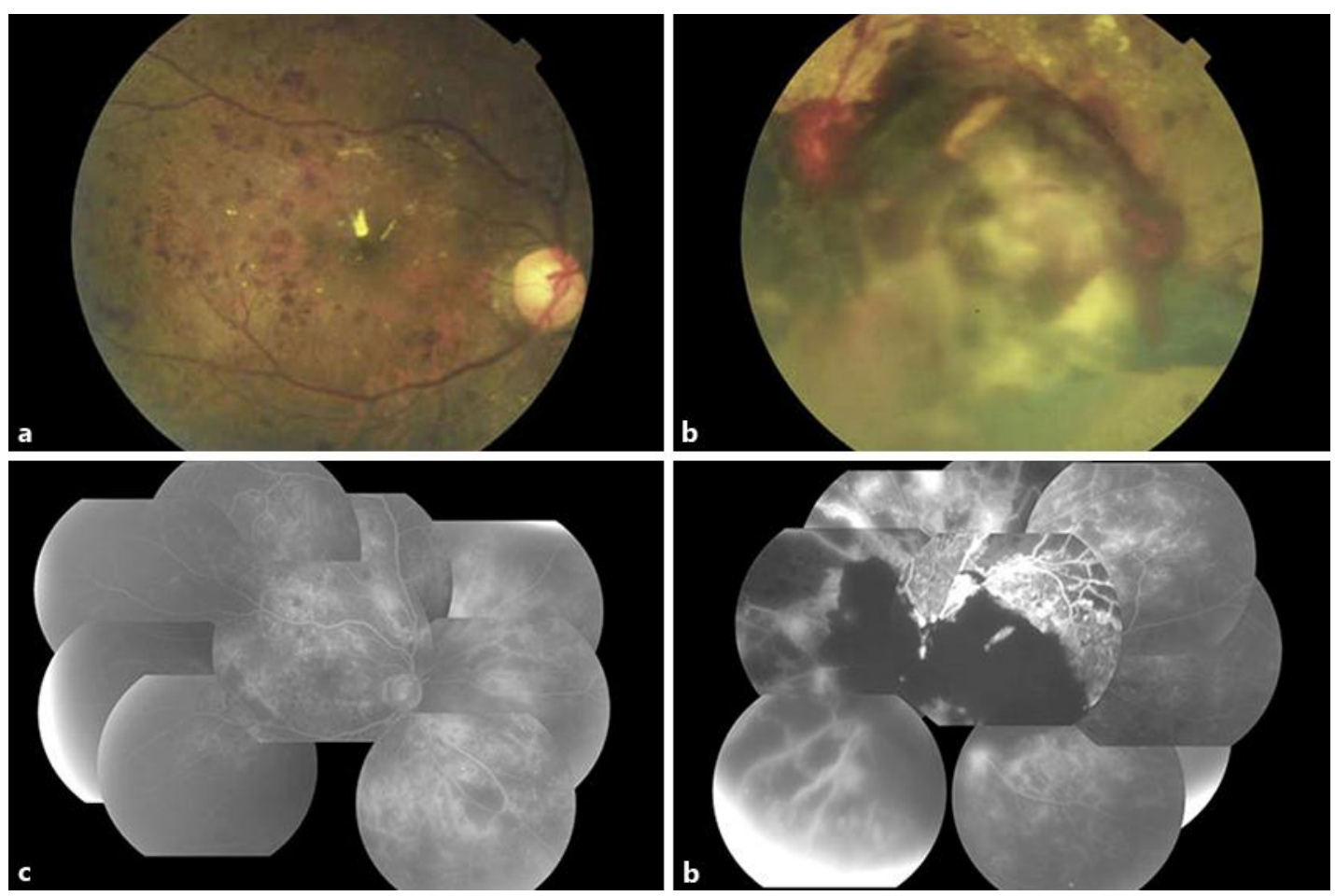

Fig. 2. Funduscopy (a right eye; b left eye) and fluorescein fundus photography (c right eye; d left eye) at initial evaluation. Pre- PDR was evident in the right eye, and highly active PDR with extensive preretinal hemorrhages was evident in the left eye. 
Case Reports in

Ophthalmology

\begin{tabular}{l|l}
\hline Case Rep Ophthalmol 2015;6:420-426 \\
\hline DOI: 10.1159/000442461 & $\begin{array}{l}\text { @ } 2015 \text { The Author(s). Published by S. Karger AG, Basel } \\
\text { www.karger.com/cop }\end{array}$ \\
\hline
\end{tabular}
www.karger.com/cop

Tajiri et al.: Vitrectomy for Proliferative Diabetic Retinopathy Associated with Klinefelter Syndrome
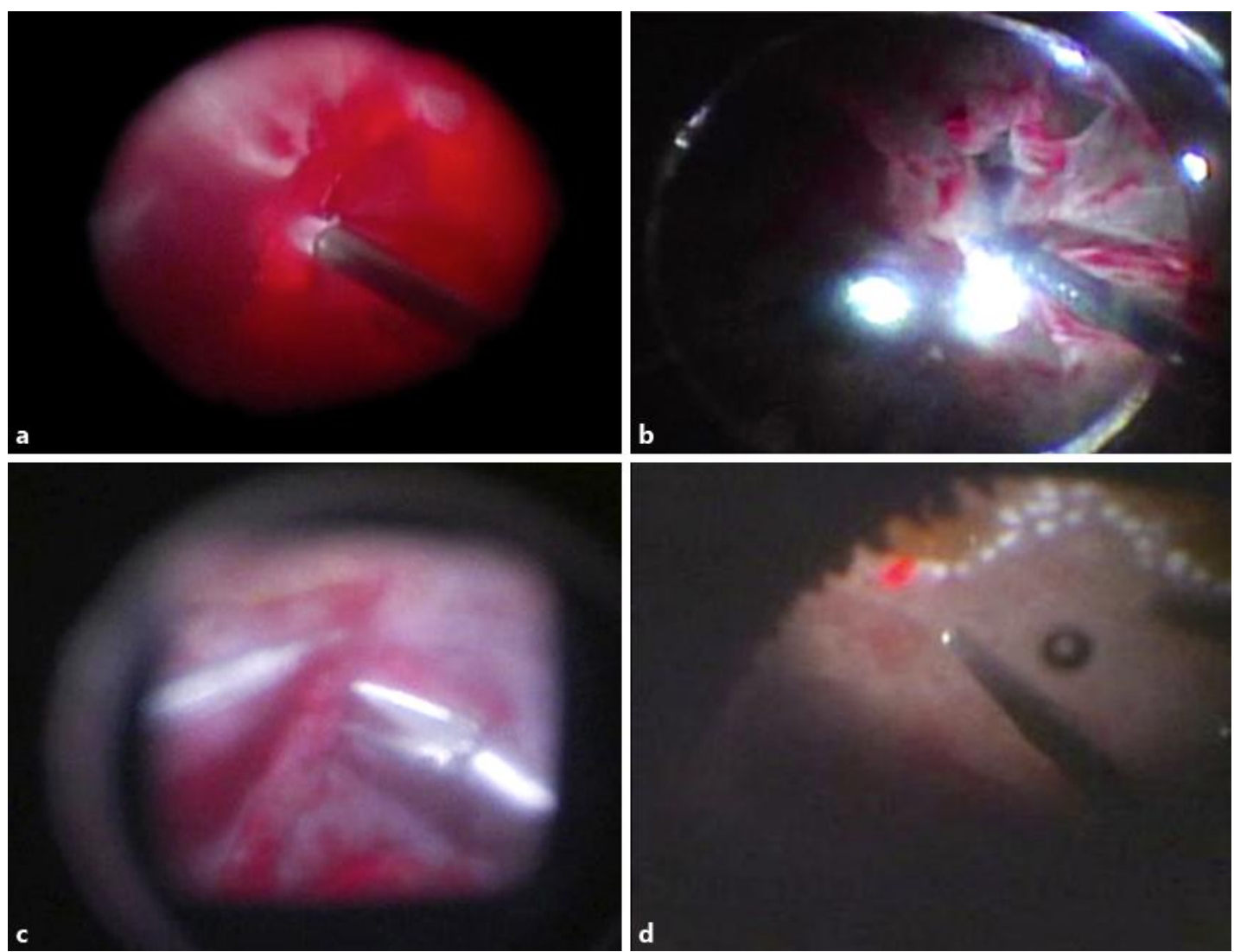

Fig. 3. Intraoperative findings during vitrectomy (a, b initial vitrectomy; $\mathbf{c}, \mathbf{d}$ repeat surgery). Extensive clotting hemorrhage during the initial vitrectomy (a). Membrane excision was continued while aspirating the blood as necessary, but multiple iatrogenic tears occurred (b). During repeat surgery, as much fibrin membrane as possible was removed from the retinal surface using vitreous forceps (c). Inferior retinectomy was required to flatten the retina, and intraocular photocoagulation was performed (d). 